\title{
Real Time IoT Application for Classification of Crop Diseases using Machine Learning in Cloud Environment
}

\author{
Tanilal Bhavsingh Thakur, Amit Kumar Mittal
}

\begin{abstract}
India is an agricultural country. A total of $61.5 \%$ of the people cultivate in India. Due to lack of agricultural land and change of weather, manytypes of diseases occur on crops and insects are born.Therefore, the production of crops is coming down. To reduce this problem, Internet of Things technology will prove to be an important role. In this system, a sensor network will be created on agricultural land using Raspberry Pi 3 model. The images of the crops will be taken by sensor cameras and these images will be sent to the cloud server via Raspberry Pi 3 model. In this proposed methodology, various image processing techniques willbe apply on acquired images for classification of crop diseases using k-means clustering algorithm with unsupervised machine learning.

This paper will also shows the method of image processing technique such as image acquisition, image pre-processing, image segmentation and feature extraction for classification of crop diseases.In bad natural environment, the farmers can produce quality crops and people will get healthy foodby this proposed methodologyand make more profit.In real time treatment of crop diseases, farmer will increase quantity of their crops.

Keywords: Crop Diseases, Image Processing, Internet of Things, Machine Learning, Raspberry Pi 3 and Sensors.
\end{abstract}

\section{INTRODUCTION}

The Internet of Things is the network of various electronic devices that communicate and sense of their internal or the external states.Internet of Things deals with ordinary objects which is used in daily life is connected to the internet shown in Fig.1. Internet of Things has some components for data communication such as sensors or devices, connectivity, data processing and user interfaces.

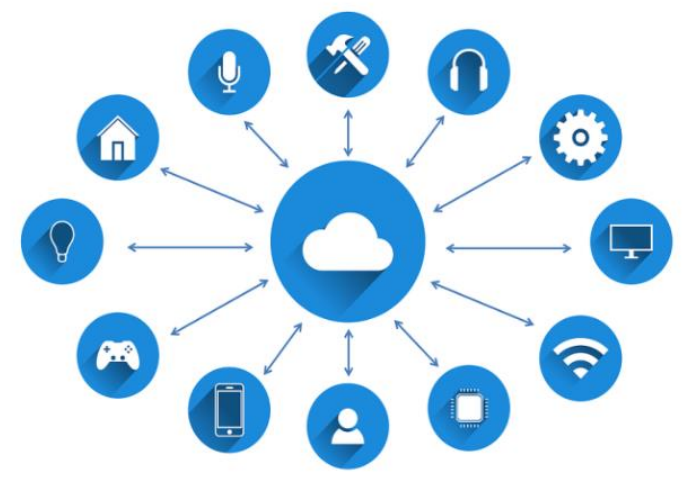

Fig. 1. Internet of Things

Revised Manuscript Received on January 03, 2019.

* Correspondence Author

Tanilal Bhavsingh Thakur, Senior lecturer, Computer Science Department, Govt Polytechnic College Barwani (MP), India.

Amit Kumar Mittal, Assistant Professor, Department of Computer Engineering, Institute of Engineering Technology, DAVV Indore (MP), India.

(C) The Authors. Published by Blue Eyes Intelligence Engineering and Sciences Publication (BEIESP). This is an open access article under the CC BY-NC-ND license (http://creativecommons.org/licenses/by-nc$\underline{\mathrm{nd} / 4.0 / \text { ) }}$
Machine learning is the concept of artificial intelligence which provides automatic learns to machine without any instruction. Machine learning is used for two reasons in IoT. First reason is the analysis of massive stored big data to obtain for smart data and second reason is related to prediction of some specific output using algorithms. In machine learning, algorithms process some inputs to generate logical outputs.

Image processing is playing a very important role in IoT. IoT based this methodology will provide the best solution for increase the crop productivity using image processing. The image processing is used for classification of image, image segmentation and feature extraction.

If someone provides service through internet, it is called cloud computing. This service can be anything like off-side storage or computing resources. Cloud computing is a style in which massively scalable and flexible IT related capabilities are provided as a service with the help of internet technology.

In this system, by creating a sensor network on agricultural landand acquired the images of crops from the sensor camera will be sent to the cloud server through internet using Raspberry Pi 3 module. In real time IoT application for classification of crop disease, there will be various image processing techniques apply for classification of crop diseases on acquired images using k-means clustering algorithm with unsupervised learning in cloud environment.

\section{RELATED WORK}

DusanMarkovic, RankoKoprivica shows the application of IoT for monitoring and controlling of agricultural production. They develop a system which is based on Arduino platform using IoT sensor nodes/devices [3].

Amandeep, Arshia, Paboni[4] develop the system for smart farming using IoT. The purpose of this paper is smart farming like smart monitoring, smart irrigation, temperature and humidity sensing usingZigBee module with different blocks, temperature sensor, humidity sensor, moisture sensor, ultrasonic obstacle sensor.

Mat, I., MohdKassim, M. R., Harun, A. N., \& Mat Yusoff, Create the wireless moisture sensor network for IoT in precision agriculture applications. The Wireless Sensor Network is a network of sensor nodes that are capable of collaborating with one another and measuring the parameters ofenvironment (i.e. light, temp, sounds, humidity etc.).

\section{Published By:}

Blue Eyes Intelligence Engineering \& Sciences Publication

(C) Copyright: All rights reserved. 
This paper presented Green House Management System is based on Wireless Sensor Network (WSN) using Moisture Sensor [5].

[6] In this paper the image processing techniques is used for detection and classificationof plant disease. The image processing is consists of some basic steps image acquisition, image preprocessing, image segmentation, feature extraction, statistical analysis and detection and classification. The $\mathrm{K}-$ Means clustering technique is used for Detection and classification of plant disease using MATLAB.

[7] In this paper the feature extraction plays an important role for identification of objects such as color, texture, morphology etc, can be used in plant or crop disease detection.

[8]Leaf disease detection and climatic parameter monitoring of plants using IoT, authors gives thought for climatic parameter such as temperature, humidity, $\mathrm{pH}$ and dry for plant and leaf sickness discovery.

[9] In this paper the authors generate the Integrated Pest Management system for prevent pest risk in effective method. Ontology is the best option for storing the information about biological, chemical etc for management of pest for controlling of plants diseases.

[10] In this paper authors developed k-means clustering algorithm for detection and classification of plant diseases using MATLAB software.

\section{PROPOSED METHODOLOGY}

Existing work does not use any machine learning algorithm to classify massive data for classification of crop disease.The current methodology does not provide a cloud environment for storing large amounts of data with deep sensory processing to capture live data with the latest technology in agricultural productivity.

The proposed methodology will provide the real time IoT application for classification of crop diseases using machine learning algorithm in cloud environment. The objective of the proposed method is classification of crop disease using image processing techniques to remove diseases of crops.

The various types of learning methods are used in machine learning such as supervised, unsupervised and reinforcement. K-means clustering algorithm is unsupervised learning. In this system k-means clustering algorithm is used for allowing input from IoT and process on it. The block diagram of proposed methodology is shown in Fig. 2.

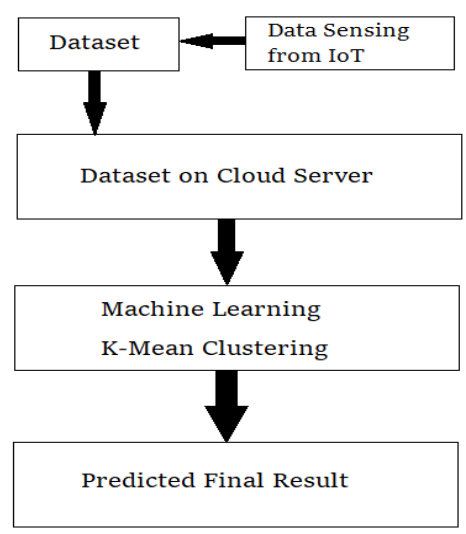

Fig.2. Block diagram of system
In this system, a sensor network will be created on agricultural land using Raspberry Pi 3 model. The images of the crops will be taken by sensor cameras and these images will be sent to the cloud server via Raspberry Pi 3 model. Raspberry Pi 3 Module will be used to capture live images of crops by sensor camera from agricultural land. Raspberry Pi 3 Module will be installed with Raspbian operating system with Noobs and create cloud server using Tomcat Apache WAMP for store live data. Java based web application code will be develops for data fetching and also configure in Raspberry Pi 3 Module. Cloud server will be configuring for computing and gathering live data from agricultural land.

\section{RESULT ANALYSIS}

In this proposed methodology, various image processing techniques will be applied on acquired images for classification of crop diseases using k-means clustering algorithm with unsupervised machine learning.

The K-means algorithm is used to fragment the image and obtainsome specific fragments of different colors for predict output. K-means clustering is a method in which large datasets are divided into clusters of similar data using Euclidian distance function with centroids. Each datasets is a set of color points of imageand can be represented in RGB primary color model. The ' $\mathrm{k}$ ' is refers to the number of cluster desired in the final output. There are some steps to the algorithm perform for desired output:

1. Initialize k centroid;

2. Assign datasets to clusters;

3. Update clusters centroid;

4. Repeat steps 2 and 3 until stop condition;

Image processing techniques is used to perform some operation on image for obtains some useful information from image using k-means clustering algorithm with unsupervised learning. The image processing is consists of followingsbasic steps shown in Fig. 3.

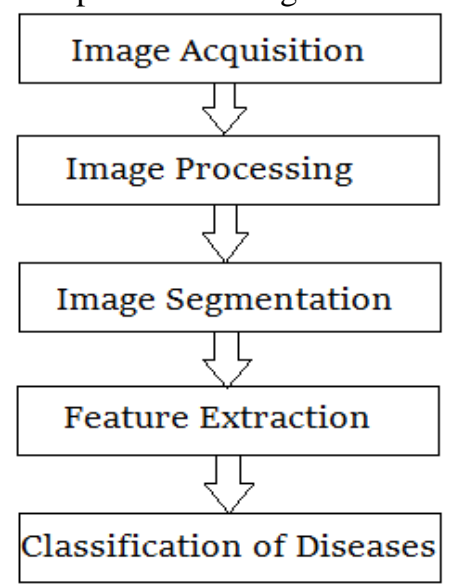

Fig. 3 Basic steps of image processing

\section{A. Image Acquisition}

The first step of image processing is the acquisition of image of crops by sensor camera from agricultural land using IoT network. The internet will provide to the IoT network by GSM standard.

Blue Eyes Intelligence Engineering

\& Sciences Publication

(C) Copyright: All rights reserved. 


\section{B. Image Pre-Processing}

Pre-processing of image is the technique for identifying the infected part of leaf image using primary RGB color. In pre-processing the primary RGB color converts into gray color shown in Fig. 4, using the Histogram equation in Java:

imGray2 = uint8(0.299*double(imR1) + 0.587*double (imG1) + 0.114*double (imB1));

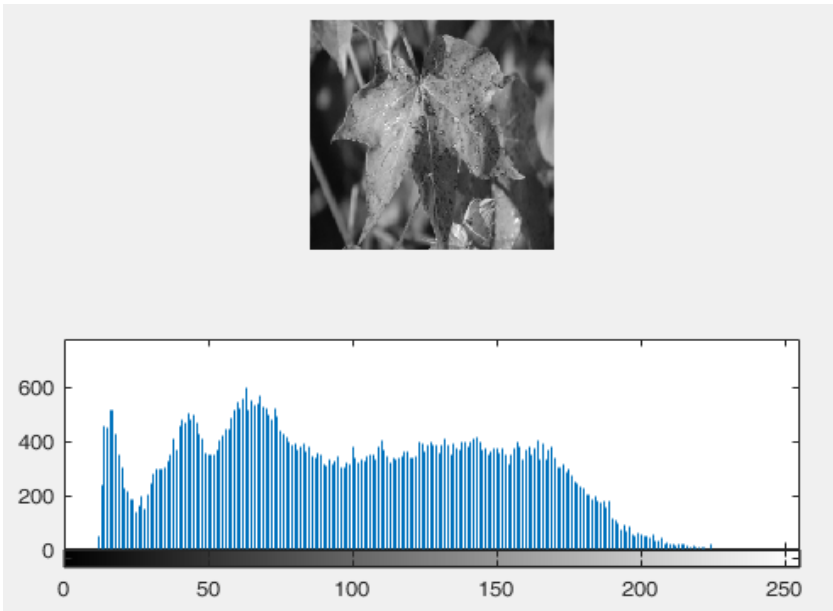

Fig. 4 Color conversion using Histogram

\section{Image Segmentation}

Image segmentation is the process of partitioning of image in various features. Segmentation is done by k-means clustering and converts primary RGB colors of image into HIS model shown in Fig.5. Segmentation is creating boundary of infected part of leaf image. $\mathrm{K}$ - Means clustering method is used to found similar cluster of pixels of infected part of image.

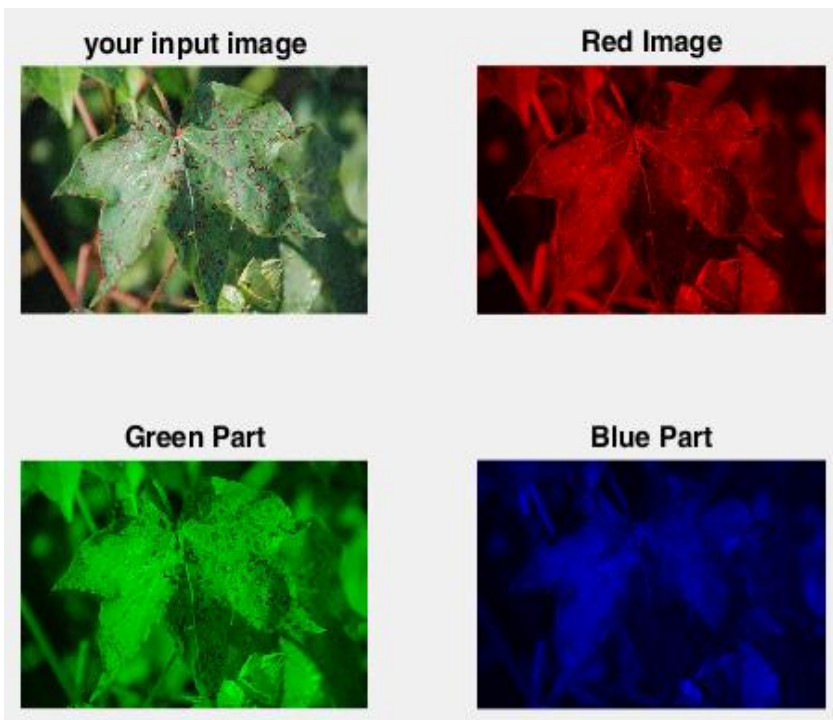

Fig. 5 Image color converted with RGB

\section{Feature Extraction}

Feature extraction is a technique which is used to representation of image matching and retrieving. Feature extraction is the most important step for extract features of leaf image of crops such as color, texture, and morphologyetc, shown in Fig. 6.
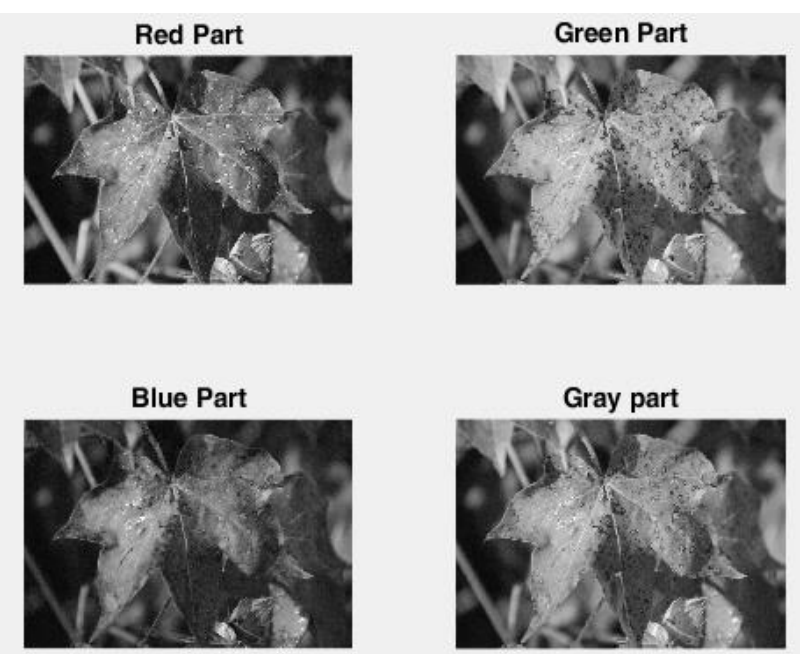

Fig. 6 Feature extraction using gray color

\section{E. Detection and Classification}

Detection and classification of diseasesby the artificial neural network (ANN), back propagation network and testing of image using machine learning in cloud environment.

\section{CONCLUSION}

The complete study of real time IoTapplication is developed to classification of crop diseases using machine learning in cloud environment.In this system crop disease is classified and identified by image processing and machine learning using artificial neural network. In bad natural environment, the farmers can produce quality crops and people will get healthy food using this proposed methodology and make more profit.In real time treatment of crop diseases, farmer will increase quantity of their crops.

\section{REFERENCES}

1. S. Bera, S. Misra, "Software-Defined Networking for Internet of Things", IEEE Internet of Things Journal (Manuscript ID: IoT-19532017.R1; Accepted on August 15, 2017).

2. Weizheng, S.,Yachun. W., Zhanliang, C., and Hongda, W.(2008) Grading Method of Leaf Spot Disease Based on Image Processing. In Proceedings of the 2008 International Conference on Computer Science and Software Engineering - Volume 06(December 12 - 14, 2008). CSSE. IEEE Computer Society, Washington, DC, 491494.

3. DusanMarkovic, UrosPesovic. "Application of IoT in Monitoring and Controlling Agricultural Production”. ActaAgriculturaeSerbica, Vol. XX, 40(2015) 145-153.

4. Amandeep, Arshia, Paboni. "Smart Farming Using IoT". IEEE Annual Information Technology, Electronic and Mobile Communication Conference, $8^{\text {th }}$ 2007, Vancouver BC Canada.

5. Mat, I., MohdKassim, M. R., Harun, A. N., \& Mat Yusoff, I. (2016) IoT in Precision Agriculture applications using Wireless Moisture Sensor Network. 2016 IEEE Conference on Open Systems (ICOS). doi:10.1109/icos.2016.7881983.

6. SachinKhirade, S. D., \&Patil, A. B. (2015). Plant Disease Detection Using Image Processing. 2015 International Conference on Computing Communication Control and Automation. doi:10.1109/iccubea.2015.153

7. H. Al-Hiary, S. Bani-Ahmad, M. Braik and Z. ALRahamneh. Fast and Accurate Detection and Classification of Plant Diseases. International Journal of Computer Applications (0975-8887) volume 17-No.1, March 2011.

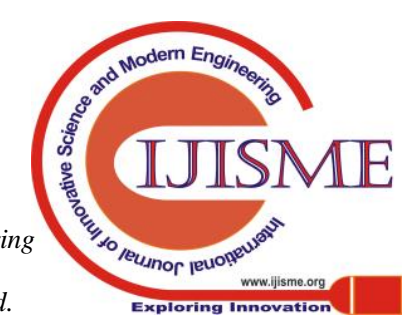


8. Dr. G.H. Agrawal, Prof. S.G. Galande, Shalaka R. Londhe. Leaf Disease Detection and Climatic Parameter Monitoring of Plants Using IoT. International Journal of Innovative Research in Science, Engineering and Technology. Vol. 4, Issue 10, October 2015.

9. Chougule, A., Jha, V. K., \&Mukhopadhyay, D. (2016). Using IoT for integrated pest management. 2016 International Conference on Internet of Things and Applications (IOTA). doi:10.1109/iota.2016.7562688.

10. SandeshRaut, AmitFulsunge. Plant Diseases Detection in Image Processing Using MATLAB. International Journal of Innovative Research in Science, Engineering and Technology. Vol. 6, Issue 6, June 2017.

11. K. Lakshmi, S. Gaythri. Implementation of IoT with image processing in plant growth monitoring system. Journal of Scientific and Innovative Research 2017; 6(2):80-83.

12. AyushKapoor, Sucheta I Bhat, SushilaShindal, AkshayMehra. Implementation of IoT(Internet of Things) and Image Processing in Smart Agriculture. 2016 International Conference on Computational Systems and Information Systems for Sustainable Solutions.@2016IEEE.

\section{AUTHORS PROFILE}

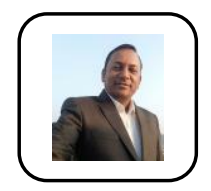

Tanilal Bhavsingh Thakur, received M.E. degree in Computer Engineering with specialization in Software Engineering from Institute of Engineering Technology, DAVV Indore MP and B.E. degree in Computer Engineering from SGSITS Indore MP. He has 17 years teaching experience and presently working as Senior lecturer in Computer Science Department, Govt Polytechnic College Barwani MP and RGPV University Bhopal MP. His research area is IoT, machine learning, artificial intelligence and cloud computing.

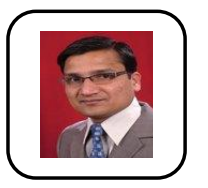

Amit Kumar Mittal, received M.E. degree in Computer Engineering with specialization in Software Engineering from Institute of Engineering Technology, Devi AhilyaVishvavidhyalaya Indore MPand B.E. degree in Computer Engineering from RGPV University Bhopal MP. He has 15 years teaching experience and presently working as Assistant Professor in the Department of Computer Engineering, Institute of Engineering Technology, DAVV Indore MP. His research area computer engineering, genetic algorithm, natural language processing. 